\title{
The Role of Motivation in Employee Retention- The Case of a Palestinian NGO
}

\author{
Xiao-Peng Yang, Hong Jiang \\ Beihang University, Beijing, China \\ E-mail: tb_1126712@163.com, hong.jiang@sina.com
}

\begin{abstract}
This paper applies the theory of organizational behavior to a practical case to solve the retention problem of a Non-Governmental Organization. According to the further investigation of the organization, we identified the root causes of the low staff retention and the findings imply some managerial recommendations for this kind of NGO.
\end{abstract}

Keywords-Motivation, Employee retention, Human resource management

\section{INTRODUCTION}

Leaders Organization is a Palestinian non-profit organization established in 2004. It focuses on promoting entrepreneurship and supporting entrepreneurs mainly in the technology sector. The organization operates several programmes and initiatives designed to support entrepreneurs including a co-working space, a startup incubator, seed investments and exchanges for entrepreneurs in key startup ecosystems around the world. The organization employs twenty staff members. It pays staff well above the average rates in Palestine. However, they have a problem in retaining the mid-level staff who is the key service provider to the organization's clients.

The organization's annual turnover for 2014 was $\$ 1.7$ million USD. The larger source of income was international development aid provided to the organization. Almost $40 \%$ of income was generated through the services provided by the organization from three main streams: Events, Incubation fees and training programmes.

Being a non-profit, the organization has many restrictions on the use of available funds. For example, although the organization can generate revenue, it is not allowed to distribute profits.

The organization has 20 staff members which can be classified into 3 experience categories: Junior level, Middle level and senior staff. The following table presents the staff structure based on the categories in Table 1

TABLE I. STAFF CATEGORIES AND SALARY RANGES

\begin{tabular}{llll}
\hline Staff Level & Number & Salary range & Staff members \\
Junior & 10 & $\$ 900-1300$ & $\begin{array}{l}\text { Reception, event managers, accountant, programme coordinators, marketing } \\
\text { coordinator }\end{array}$ \\
Middle Level & 6 & $\$ 1500-2800$ & $\begin{array}{l}\text { Consultants to entrepreneurs, programme managers, project managers, } \\
\text { incubation programme manager }\end{array}$ \\
Senior & 4 & $\begin{array}{l}\text { Director, Director of Operations, Director of Finance, Business Development } \\
\text { Director }\end{array}$ \\
\hline
\end{tabular}

Generally speaking, the organization pays well above the average salaries for similar positions in Palestine. For example the average for entry level salaries is $\$ 600$, Middle level staff on average earns $\$ 1000$ and senior staff earn in the range of $\$ 2000$.

Despite the terms of employment being above average in Leaders Organization, the Organization has problems in retaining employees mainly at the middle level of the organization. This weakness is critical for the organization because employees at this level are the employees that deliver the organization's services to its clients. They usually reach these positions after years of training and internal development that allows them to deliver these services. Once they leave, the organization has to invest in new staff members to deliver these services.

\section{LITERATURE REVIEW}

The most important concept is about the motivation. Motivation is defined as what causes people to behave as they do, and is a consequence of an interaction between the individual and the situation. The second concept is performance. Performance is mainly about what the employees present during the work. Works are also important for the case and can help us figure out the cause of retention. Works are separated into 3 different concepts which are work preference, work involvement and work satisfaction. Work preference indicates which kind of work is popular among the middle-level staffs. From work preference we can know their attitude about work. Work satisfaction is the summary of preference and involvement. The research also has to base on emotion, attitude, perception, communication and 
relatedness. Emotion includes anger, fear, sadness, happiness, disgust and surprise and can be separated into positive and negative emotions. Attitude is the result of emotion and environment. Perception is a process by which individuals organize and interpret the information in order to give meaning to their environment. Feelings of relatedness that are close to inexistence in the organization, negatively determine motivation and well-being in the work context.

Employees are more and more important in the competitive labor market. Researchers have been interested in employee motivation and commitment. Theories of work motivation come from more general theories of motivation. It's used for explaining the task performance. In contrast, commitment comes from sociology and social psychology. They are all difficult to define concept. Different researchers in different disciplines have various meaning. So Meyer et al. [1] propose an integrative framework to solve it. Vallerand R $\mathbf{J}$ et al. [2] reviewed self determination theory (SDT) reflects the quality and creativity of the research conducted by Canadian motivation researchers. Rynes et al. [3] have a research on discrepancies between what people say and do with respect to pay. The result is false that employees are likely to over report the importance of pay in employee surveys.

\section{METHODS AND RESULTS}

Work turnover certainly represents one of the most important issues for any organization. Indeed, the money and time invested in hiring and training an individual who leaves the organization is lost forever. In addition, such costs are significant and increase as we move up the organizational hierarchy. Therefore, we conduct an in-depth human resource audit (refer with Table 2) to indentify the problems involving all the phases of the recruitment process.

TABLE II.KEY FINDINGS OF THE HR AUDIT

\begin{tabular}{|c|c|c|}
\hline Step & Description & Implications \\
\hline Recruitment & $\begin{array}{l}\text { Highly Competitive. Focus on Skill first, then } \\
\text { attitude. }\end{array}$ & $\begin{array}{l}\text { Very expensive and long process to identify } \\
\text { ideal candidate }\end{array}$ \\
\hline Pay determination & $\begin{array}{l}\text { Salary Scale; Employee's history; Employee } \\
\text { importance }\end{array}$ & $\begin{array}{l}\text { Limited transparency; room for inequity; } \\
\text { flexibility in recruiting highly qualified staff }\end{array}$ \\
\hline Development & $\begin{array}{l}\text { Transfer of Knowledge, high development for } \\
\text { entry level }\end{array}$ & $\begin{array}{l}\text { Improved staff capacity; relevance to service } \\
\text { needs. }\end{array}$ \\
\hline Promotion & Track record of internal hiring & Provides motivation and drives initiative \\
\hline Evaluation & No transparent system & lack of transparency in decision making. \\
\hline
\end{tabular}

The key problem identified involves the recruitment process. Due to the well planned and applied recruitment process, employees seem to find that their work is positively correlated with their skills and education. Their tasks are overall at the same level with their knowledge but there is a lack of positive feedback from the general managers.

Although the effort and resources are well spent, the process can be in vain, if the future employees decide to trade in for a new job in the near future. We saw that the main focus is on skills and past training and then on attitude. We observed that attitudes are strongly correlated with job satisfaction and job involvement. That is why the hiring process should have a strong emphasis on attitudes and not only on training and education. Job involvement is related to job satisfaction-people identify with their job and consider their performance level important to self worth. Employees with a high level of job involvement identify with and really care about the kind of work that they do.

Also another objective for the recruitment process should be an evaluation of psychological empowerment. Psychological empowerment is also closely related to job satisfaction, employee's beliefs in the degree to which they influence their work environment, their competence, the meaningfulness of their job, and their perceived autonomy, that can over time decrease job turnover, if it is closely observed.

As it comes to career advancement opportunities and career development opportunities our research implies that there is a strong motivation when it comes to the possibility of promotion, as promotions are made internally.

Our second step was to observe motivation by doing Skype interview of the workers and managers in Leaders Organization. The results are showed below in Table 3 . Competence and relatedness are important determinants of motivation. Any event that affects these feelings will also influence motivation. Payment was not a significant determinant of motivation. Having sufficient compensation will not lead to passion for a job. Motivation, according to the theory, is determined not by material incentives, but rather by interesting work, recognition, and personal growth. Feelings of relatedness that are close to inexistence in the organization, 
negatively determine motivation and well-being in the work context.

Concluding from our research we observed a lack of perceived organizational support. Employees do not seem to identify with the values of the organization and they do not see that their contribution is appreciated, as there is a lack of feedback on all levels in the company.

\section{TABLE III. KEY FINDINGS OF THE INTERVIEWS}

\begin{tabular}{|c|c|c|c|}
\hline Relatedness & $\begin{array}{l}\text { Employees generally reported good } \\
\text { relationship with colleagues }\end{array}$ & Satisfaction & $\begin{array}{l}\text { Work satisfaction was correlated with } \\
\text { internally motivated }\end{array}$ \\
\hline Competence & $\begin{array}{l}\text { Employees viewed tasks relevant to their } \\
\text { skills and capacity }\end{array}$ & Exhaustion & $\begin{array}{l}\text { Some employees who are intrinsically } \\
\text { motivated have reported burnout }\end{array}$ \\
\hline Task & $\begin{array}{l}\text { Majority of employees indicated rewarding } \\
\text { and challenging job but limited constructive } \\
\text { feedback }\end{array}$ & Retention & $\begin{array}{l}\text { intent of leaving was determined among } \\
\text { externally regulated staff }\end{array}$ \\
\hline Motivation & $\begin{array}{l}\text { diverse results regarding source of motivation } \\
\text { (intrinsic/extrinsic) and regulation }\end{array}$ & & \\
\hline
\end{tabular}

\section{CONCLUSIONS AND RECOMMENDATIONS}

Overall, from the study above, we identified the root causes of the low staff retention. A lack of positive feedback from the general managers is the primary cause, if the contribution of the employee is appreciated by the managers promptly, the workers will feel more motivated and less likely to leave the company. Another finding is that the perceived autonomy, meaning that the employees believe their influence and competence of the job, can decrease job turnover.

Those findings imply some managerial recommendations for this kind of NGO.

First, this NGO should better increase emphasis on attitude during recruitment process, in other words, recruit attitude instead of skill, otherwise it will be very expensive and long process to identify ideal candidate.

A second recommendation is that this NGO introduce non-monetary reward system to reduce the impact of emotional exhaustion. A tangible non-monetary incentive may increase the perceived value of the award, the perceived utility of earning an incentive, or increase the likelihood that an employee will exert additional effort at a specific point in time.

Third, we recommend this NGO to introduce policies that address needs of extrinsically motivated staff, such as bonuses.
Fourth, institutionalize a clear and transparent employee evaluation system which means allowing the employee to see what is documented about them, a totally transparent system to "paint a picture" of the employee.

A fifth recommendation of this study is that this NGO combine both bottom-up and top-down form of feedback. Top-down is the most traditional form in which manager/supervisor feeds back to subordinate based on observation, quality of work, relationship, etc. While in the form of bottom-up, employee provides indirect feedback to manager via a rating system based on communication skills, decision making, and clarity of objectives. These two forms are ineffective by themselves, breakthrough improvements in retention can only be achieved by blending the two.

\section{REFERENCES}

[1] Meyer J P, Becker T E, Vandenberghe C, "Employee Commitment and Motivation: A Conceptual Analysis and Integrative Model", Journal of applied psychology, vol.89, no.6, p.991, 2004.

[2] Vallerand R J, Pelletier L G, Koestner R, Reflections on Self-Determination Theory, Canadian Psychology/Psychologie canadienne, vol.49, no.3, pp.257, 2008.

[3] Rynes S L, Gerhart B, Minette K A, "The Importance of Pay in Employee Motivation: Discrepancies between What People Say and What They Do", Human resource management, vol.43, no.4, pp. 381-394, 2004 